\title{
Editorial
}

\section{Child protection in the context of the pandemic Sathiadas MG}

Children are a vulnerable group to any stress in family, society and the environment. Schools have started to open in a graded manner after periods of closure, travel restrictions and social isolation following the pandemic. Children and families who are already vulnerable due to socio-economic exclusion or those who live in overcrowded settings are particularly at risk of stigma and discrimination. [1]

Recent statistics from the Department of child probation Northern Province has indicated a rise in sexual abuse by $11.3 \%$ and school dropout by $12.6 \%$ from 2019 to 2020 . Marked increase can be predicted for the year 2021 as schools have started to function on a regular basis. The socio-ecological disruption with limited access to basic facilities is the key component predicted to contribute to the increase in issues related to child protection. There are other factors that contribute towards child protection mainly the loss of support that was present during school time. Lack of earning, family separation, caregiver distress and fear of illness promotes the risk of abuse, neglect, violence and exploitation. [2] Due to the disruptions in movement and the school closures teachers, childcare workers, coaches, extended family and community members and child and family welfare workers, were not in regular contact with children.

Children may undergo abuse in the form of physical, sexual abuse and neglect. They may also increasingly witness intimate partner violence. One of the key reasons for school dropout may be that children start to contribute to the family's financial need by engaging in work. According to the Latest National Child Activity Survey (2016) report, Child Labour in Sri Lanka accounts for 1 percentage but further reduction is predicted to hinder the reduction during the pandemic. [3] In fact, the International Labor Organization and Vol.33, No.2, Dec 2021
UNICEF forecast that by 2022 the increase in poverty associated with COVID-19 is likely to increase child labor by 8.9 million. [4] These children do not return to school even if the situation normalizes due to the psychological stress of isolation which prevents them from continuing to develop healthy emotions. [5] Governments and stakeholders have to take actions to overcome the child labour by educating and creating awareness, financial assistance, providing home learning resources and create a monitoring process.

One of the other problems faced due to unemployment in adults is the increasing nature of family conflict especially the adult adolescent conflict. Recognizing these shifts in family ecology is critical to health providers' ability to screen for mental health, assess existing family supports, and provide timely, targeted information about stress management and contending with family conflict. [6]

The increased risk of child marriages is a coping strategy to overcome the financial burden of the family. School closures and interruptions in the girl's education hastens the arrangement of child marriage.

School closures and graded reopening of the schools have led to the children learning and socializing more online. Spending more time on virtual platforms can leave children vulnerable to online sexual exploitation and grooming, A lack of face-to-face contact with friends may lead to heightened risk-taking such as sending sexualized images, while increased and unstructured time online may expose children to potentially harmful and violent content leading towards a greater risk of cyberbullying. [7] We have witnessed several instances of cyberbullying during the pandemic in Sri Lanka. To safeguard children from online abuse the safety of online platforms must be enhanced. In addition, the schools should monitor 
good online behaviour and ensure children have continued access to school based counselling services. Parents too have a role in safeguarding their children especially updating the software and installing antivirus programmes, having open dialogues with children, establishing rules on internet use and know the distress signs in children that emerge when they are online.

Children are at a high risk of exploitation, since school closures more children are forced on to the streets in search of food and income, has heightened the chance of infection and exploitation. Child trafficking in the form of sex trafficking, forced labor, forced begging and debt bondage will increase and has become more difficult to detect during the pandemic due to the fact the perpetrators also adopt to the new normal especially through the technologies in communication. The root causes of child trafficking are the economic and societal inequalities which are exacerbated with the pandemic. Identifying the victim of trafficking is very difficult as most of the time the victims are exploited illegally, informally and in unregulated circumstances. Lack of willingness to report their victimization and limited law enforcement capacities to detect this crime have also contributed to this crime. [8] Anti-trafficking responses must continue to be based on human rights, while access to health care and social support without discrimination should be guaranteed.

Children are our future and it is our utmost duty to protect and safeguard them during this trying time of the pandemic.

\section{Reference:}

1. UNICEF report on child protection during the pandemic: https://data.unicef.org/topic/childprotection/covid-19/

2. WHO report of child protection: https://www. who.int/pmnch/covid-19/toolkits/child/childprotection/en/
3. Labour Department Sri Lanka report 2016. https://www.ilo.org/colombo/info/pub/pr/ WCMS_758216/lang--en/index.htm

4. Jonas F. Ludvigsson, Systematic Review of COVID-19 in children shows milder cases and a better prognosis than adults (Acta Paediatrica, March 20, 2020), accessed May 20, 2020,https://www.researchgate.net/ publication/340100284_Systematic_review_ of_COVID19_in_children_show_milder_ cases_and_a_better_prognosis_than_adults.

5. Iosua, E. E., Gray,A. R., McGee, R., Landhuis, C. E., Keane, R., \&Hancox, R. J. (2014).Employ ment among schoolchildren and its associations with adult substance use, psychological wellbeing, and academic achievement. Journal of Adolescent Health, 55(4), 542-548.

6. Ming-Te Wang, Daphne A. Henry, Juan Del Toro, Christina L. Scanlon, Jacqueline D. Schall, COVID-19 Employment Status, Dyadic Family Relationships, and Child Psychological Well-Being, Journal of Adolescent Health, Volume 69, Issue 5,2021, Pages 705-712, ISSN 1054-139X, https://doi.org/10.1016/j. jadohealth.2021.07.016.

7. UNICEF report on Children at increased risk of harm online during global COVID-19 pandemic: https://www.unicef.org/maldives/ press-releases/children-increased-risk-harmonline-during-global-covid-19-pandemicunicef

8. UNDOC document on impact of the pandemic on child trafficking; https://www.unodc.org/ documents/Advocacy-Section/HTMSS Thematic_Brief_on_COVID-19.pdf 